\title{
An Analysis of the Extraction Technologies: Fruit Peel Waste
}

\author{
Nidhiben PATEL ${ }^{1}$, Antra KALNBALKITE ${ }^{2}$, Dagnija BLUMBERGA ${ }^{3}$ \\ ${ }^{1-3}$ Department of Environmental Protection and Heat Systems, Faculty of Environmental Science, \\ Riga Technical University, Azenes iela 12-K1, LV1048, Riga, Latvia
}

\begin{abstract}
Advances in technology over the past few years have allowed us to evolve from waste to value. Food waste has been an increased recognition that more attention needs to be paid to this area. With this concern, research on fruit waste valorization into medicinal products has a rich background. This paper approaches the problem with a broader perspective by introducing the fruit waste valorization pathway. The key idea in this paper is to use the multi-criteria analysis method to choose the best essential oil extraction technique from fruit waste. The performance of four different extraction methods i.e., steam distillation, cold-pressing, solvent extraction, and hydro distillation compared in the approach, considering the environmental, economic, social, and technical criteria. The methodology was developed with two scenarios, by using the Analytic hierarchy process (AHP) and Technique for Order of Preference by Similarity to Ideal Solution (TOPSIS) methods. Our research highlighted that cold-pressing extraction is the most effective technique for essential oil extraction in both scenarios.
\end{abstract}

Keywords - Bioresources; medicinal use; multi-criteria analysis; valorization pathway

\section{INTRODUCTION}

With the worldwide increasing population, production and cultivation of fruits and vegetables is also increasing. Besides, food waste has long-lasting footprints in terms of landfills and socio-economic impacts due to the higher moisture and biodegradability [1]. Therefore, food waste management is becoming a major concern over the world but with advanced technology, food waste can be a versatile environmental bioresource that can be converted to biofuel, value-added products, and biomaterial [2].

This research particularly focuses on the fruit waste valorization pathways because enormous studies have been done on the conversion of fruit waste into landfills, anaerobic digestion, composting, etc. [3]. Pfaltzgraff et al. argue that fruit waste is not only a wide source of energy but also has incredible ability to produce industrial products such as essential oil, medicines, cosmetics, organic amendment, etc. [4]. Each part of a fruit, for example, peel, pulp, and seed have a unique residual and chemical composition that can be used to produce various organic products.

Traditionally, fruit peels are the most common waste that can be easily found in the environment. Fruit peels have the best medicinal properties such as antimicrobial, antioxidant, anti-inflammatory, anti-healing, anti-infectious, anti-mutagenic, and hepatoprotective. Essential oil is one of the crucial extractions from fruit peels, researchers have been discovered after several experiments that essential oil has antimicrobial activity

*Corresponding author.

E-mail address: nidhiben-arvindbhai.patel@rtu.lv 
against bacteria, moulds, yeasts, pathogenic and phytopathogenic microorganisms. As a result, it has been proven that essential oil can be used to confront the microorganisms to the antibiotics [5]. To support the current research some of the examples are mentioned in Table 1.

TABLE 1. Fruit WASte Into Medicinal Use

\begin{tabular}{lllll}
\hline Fruit waste & $\begin{array}{l}\text { Value-added } \\
\text { product }\end{array}$ & Medicinal use & Methods & Reference \\
\hline Banana peel & Essential oil & Antioxidant property & Extraction & {$[5]$} \\
Citrus peel & Essential oil & $\begin{array}{l}\text { Alleviates pain } \\
\text { Relieves inflammation } \\
\text { Dissolve's gallstones }\end{array}$ & Extraction & {$[6]$} \\
Orange peel & Essential oil & $\begin{array}{l}\text { Antimicrobial activity } \\
\text { Flavoring agent of } \\
\text { medicine }\end{array}$ & $\begin{array}{l}\text { Steam distillation } \\
\text { Cold pressing } \\
\text { Solvent extraction }\end{array}$ & {$[5],[7]$} \\
Mango peel & Pectin & Enfleurage & \\
Grapefruit peel & Essential oil & Health benefits & Extraction & {$[8]$} \\
& & $\begin{array}{l}\text { Antibacterial and } \\
\text { Antioxidant properties } \\
\text { Biopesticide against } \\
\text { mosquito larvae }\end{array}$ & Paper disc diffusion & {$[9]$} \\
\hline
\end{tabular}

One of the essential components that can be derived from fruit peel (apple pomace, citrus, sugar beet pulp) is pectin. Earlier research shows that pectin is an effective component at the industrial level and also useful in the medical treatment of cancer, cell apoptosis, and cholesterol [10]. Several studies have discovered that fruit peel waste has a potential application to medicinal products.

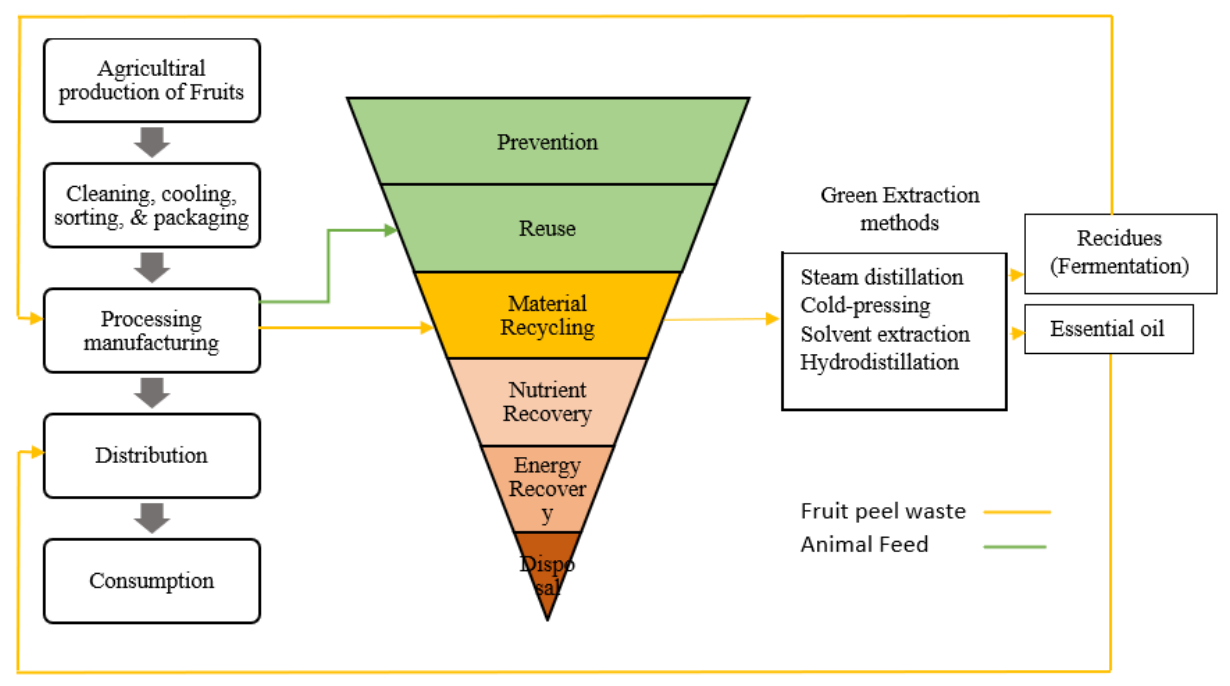

Fig. 1. Essential oil extraction pathway. 
Essential oils term is also referred to as volatile oils, ethereal oils, or aethrolea, which contain the essence of a plant fragrance. It is a concentrated hydrophobic liquid, naturally derived from plants [11]. A recent systematic review investigated the extensive use of essential oil in the cosmetic industry, daily life due to the fragrance [12], and pharmaceutical industry [13], which shows the increasing demand for essential oil in the market. A variety of methods can be reliably utilized for extraction. Fig. 1 shows the clear vision of the extraction pathway of essential oil from fruit waste. Here, we presented the essential oil extraction from the fruit peel waste. In the next chapter, a multi-criteria analysis is performed to choose the best extraction technology.

\section{Methodology}

The methodology consists of literature review, then it further goes with multiple-criteria decision analysis (MCDA), using Analytic hierarchy process (AHP) with Technique for Order of Preference by Similarity to Ideal Solution (TOPSIS), after receiving results, which need to be analysed, conclusions should be drawn.

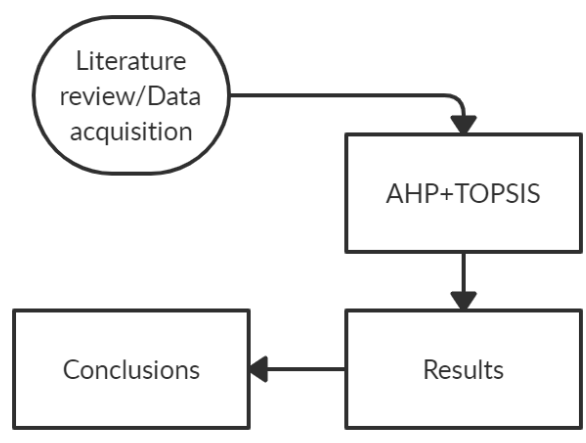

Fig. 2. Research methodology.

MCDA is used to make decisions and analyse the significance of objectives from various types of information and data - qualitative and quantitative data, data from the physical and social sciences, and from politics and ethics to evaluate problem solutions.

TABLE 2. SCALE FOR PAIRWISE COMPARISON

\begin{tabular}{ll}
\hline Scale & Definition \\
\hline $\mathbf{1}$ & Equally importance \\
$\mathbf{2}$ & Equally to moderate importance \\
$\mathbf{3}$ & Moderately importance \\
$\mathbf{4}$ & Moderately to strongly the importance \\
$\mathbf{5}$ & Strongly importance \\
$\mathbf{6}$ & Strongly to very strongly importance \\
$\mathbf{7}$ & Very strongly importance \\
$\mathbf{8}$ & Very to extremely strongly the importance \\
$\mathbf{9}$ & Extremely importance \\
\hline
\end{tabular}


The next step is to identify the criteria weights using AHP. AHP method divides and analyses problems in a hierarchical structure consisting of a goal, a criterion, and a subcriterion. The AHP methodology was developed in 1980 by Saaty, and the selected criteria are compared in pairs by experts [14]. Researchers from the Institute of Energy Systems and Environment at Riga Technical University are the experts to define the selected criteria for pairwise comparison. Table 2 provides the scale for pairwise comparison adapted from Saaty Thomas L.

The comparison matrix comprises criteria, where each criterion is compared with all other criteria. The next step is to solve the problem of eigenvectors by which the criteria will be arranged. The sum of each column of the pairwise comparison matrix is then calculated and used to divide the corresponding column values, thus normalizing the comparison matrix. The values of each row are then summed and divided by the number of criteria to calculate the eigenvector for each row of the matrix. Eigenvectors indicate the ranking (weight) of the criteria. AHP methodology can be implemented in three main steps. Each step needs to be performed to be resolved in a decision-making matrix with AHP is described below.

- Step 1: Define the objective, selected criteria, and alternatives;

- Step 2: Here, elements can be compared to one another, two at a time, concerning their importance on an element above them in the hierarchy and then structured the comparison matrix;

- Step 3: Geometric mean is used to combined questionnaires for all experts and based on the combined questionnaire the problem is solved;

- Step 4: Weights for pairwise comparisons are calculated;

- Step 5: After calculating weights, decision matrixes are formed;

- Step 6: Final weights of alternatives obtain by multiplying decision matrixes from alternatives toward criteria;

- Step 7: Weights obtained in the last step are raw and need to be normalized to be easily comparable;

- Step 8: Inconsistency and weights of pairwise comparisons are calculated. Consistency Index $(C I)$ is calculated by Eq. (1) proceeded by Consistency Ratio $(C R)$ in Eq. (2).

$$
C I=\frac{\lambda_{\max }-n}{n-1}
$$

where $\lambda_{\max }-$ maximum eigenvalue;

$$
C R=\frac{C I}{R I}
$$

where $R I-$ Random Index that varies for different matrix.

The next step in the methodology is to use the TOPSIS method. TOPSIS is a popular MCDA developed by Hwang and Yoon in 1981. The method uses the best alternative and worst alternative to define the best alternative [15]. TOPSIS method has been used to compare the possible use of production residues in producing value-added products, such as single-cell oil, from different factories, described in Racko E. et al. [16]. The main advantages of TOPSIS are the opportunity of an infinite number of criteria and alternatives, a comparatively simple calculation method, and no need for specific software or specific programming techniques. TOPSIS results provide comparing alternatives in a useful and simply comprehensible form. There should be selected alternatives for the evaluation, which are 
evaluated by four criteria: technological, economic, environmental, and social. The first step using the TOPSIS method is the normalization of the decision-matrix, followed by calculating the normalized decision-matrix and the best and worst solutions. The best solution corresponds to a theoretical option of the most desirable level of each criterion, while the worst solution corresponds to a theoretical option of the least desirable level of each criterion. Finally, the distance of each alternative is calculated that further allows obtaining the closeness coefficient for the ranking alternatives. Alternatives rank from best to worst [17], in detailed equations for the TOPSIS method that is used in this study are described below.

Step 1: Normalized matrix value can be derived by multiplication of normalized value and weight which is done by following Eq. (3).

$$
v_{a i}=w_{i} \cdot r_{i a}
$$

where

$v_{a i} \quad$ Weighted value;

$w_{i} \quad$ Weight, $w_{i 1}+w_{i 2}+\ldots+w_{i m}=1, w_{i}=1 \ldots m$;

$r_{i a} \quad$ Normalized criterion value.

Step 2: Distance for each ideal and non-ideal alternative can be calculated by the sum of the squares of weighted criterion values. The calculation can be done by following Eq. (4). and Eq. (5).

$$
d_{a}^{+}=\sqrt{\sum_{j=1}^{n}\left(v_{i}^{+}-v_{a i}\right)^{2}},
$$

where

$d^{+}{ }_{a} \quad$ Distance for each action to the ideal solution;

$v_{i}^{+} \quad$ Ideal solution.

$$
d_{a}^{-}=\sqrt{\sum_{j=1}^{n}\left(v_{i}^{-}-v_{a i}\right)^{2}},
$$

where

$d_{a} \quad$ Distance for each action to the non-ideal solution;

$v_{i}^{-} \quad$ Non-ideal solution.

Step 3: Closeness coefficient (Ca) shows the distance to the non-ideal solution, which is determined by Eq. (6).

$$
C_{a}=\frac{d_{a}^{-}}{d_{a}^{+}+d_{a}^{-}},
$$

where

$d^{+}{ }_{a}+d^{-}{ }_{a} \quad$ Sum of the distance to the non-ideal solution;

$d_{a}{ }_{a} \quad$ Distance to the non-ideal solution.

Our approach is to analyse the best extraction method to extract the essential oil from the fruit waste by using multi-criteria analysis. 
TABLE 3. OVERVIEW OF THE SELECTED CRITERION

\begin{tabular}{|c|c|c|c|c|}
\hline $\begin{array}{l}\text { Extraction } \\
\text { methods }\end{array}$ & Technical aspect & $\begin{array}{l}\text { Environmental } \\
\text { aspect }\end{array}$ & Economical aspect & Source \\
\hline Steam distillation & $\begin{array}{l}\text { Pressurized } \\
\text { container required }\end{array}$ & $\begin{array}{l}\text { Less fuel \& } \\
\text { High temperature } \\
\text { required }\end{array}$ & $\begin{array}{l}\text { High equipment \& } \\
\text { operating cost }\end{array}$ & {$[18]$} \\
\hline Cold pressing & $\begin{array}{l}\text { High-quality } \\
\text { production } \\
\text { possibility }\end{array}$ & $\begin{array}{l}\text { Lack of hazardous } \\
\text { organic solvent \& } \\
\text { environmentally } \\
\text { friendly }\end{array}$ & $\begin{array}{l}\text { Low cost \& less } \\
\text { manpower required }\end{array}$ & [19] \\
\hline Solvent extraction & $\begin{array}{l}\text { Simple equipment } \\
\text { used, Low } \\
\text { efficiency }\end{array}$ & $\begin{array}{l}\text { High temperature } \\
\& \text { production of } \\
\text { hazardous waste }\end{array}$ & Low cost & {$[19]$} \\
\hline Hydro distillation & $\begin{array}{l}\text { Simple } \\
\text { instrumentation }\end{array}$ & $\begin{array}{l}\text { High consumption } \\
\text { of energy, no } \\
\text { organic solvent }\end{array}$ & Low cost & {$[20]$} \\
\hline
\end{tabular}

Here we compare the performance of four different green extraction methods like steam distillation, cold-pressing, solvent extraction, and hydrodistillation. The selection of the criterion i.e., technical, environmental, economic, and social acceptability is based on the vast literature analysis. Table 3 shows the detailed overview of the selected criteria and subcriteria. These techniques are used in the evaluation to extract the essential oil from the fruit waste. Steam distillation is a separation technique, can be applied for the separation of volatile organic compounds [21]. Earlier studies show that $93 \%$ of the proportion of essential oil can be extracted by steam distillation [22]. The cold-pressing method is the standard technique used to extract essential oil from the seeds of plants and fruits. Also, this process can be done at a low temperature below $60{ }^{\circ} \mathrm{C}$ [23]. The solvent extraction method is also known as liquid-liquid extraction, is a method to separate compounds based on the solubility of their parts [24]. Hydro distillation is a traditional method used to extract oil or bioactive compounds from plants [25]. Overall, comparatively all four methods have different functionality and apparatus.

\section{Results}

The author compared technological, economic, environmental, and social criteria pairwise. Results of the pairwise comparison of AHP are shown in Table 4.

TABLE 4. AHP PAIRWISE COMPARISON MATRIX OF CRITERIA

\begin{tabular}{lcccc}
\hline \multicolumn{1}{c}{ Criteria } & Technological & Economical & Environmental & Social \\
\hline Technological & 1 & 3 & 2 & 4 \\
Economical & 0.33 & 1 & 2 & 3 \\
Environmental & 0.5 & 0.5 & 1 & 4 \\
Social & 0.25 & 0.33 & 0.25 & 1 \\
\hline
\end{tabular}


The authors calculated the weights of the criteria after the normalization of the matrix. The results show that the weight of the technological criterion is the most important -0.45 , then as the second most crucial weight is economical -0.25 , then the third and fourth criteria are environmental and social, which -0.22 and 0.08 , respectively.

The comparisons are consistent and used in the following calculations, considering that the value of the consistency rate is $C R=0.079$. If the $C R$ is less than or equal to 0.1 , then the discrepancy is acceptable, but the subjective assessment must be reconsidered if it is higher than 0.1 .

TABLE 5. TOPSIS DECISION-MAKING MATRIX

\begin{tabular}{lllll}
\hline Alternative technologies & \multicolumn{4}{c}{ Criteria } \\
\hline & Technological & Economical & Environmental & Social \\
Steam distillation & 4 & 4 & 3 & 4 \\
Cold-pressing & 4 & 5 & 4 & 3 \\
Solvent extraction & 3 & 3 & 3 & 4 \\
Hydrodistillation & 3 & 3 & 4 & 4 \\
\hline
\end{tabular}

The potential for using the four technologies was rated on a scale from 1, which corresponds to the lowest rating, to 5 , which corresponds to the highest rating. Table 5 are shown the evaluation values in a decision-making matrix.

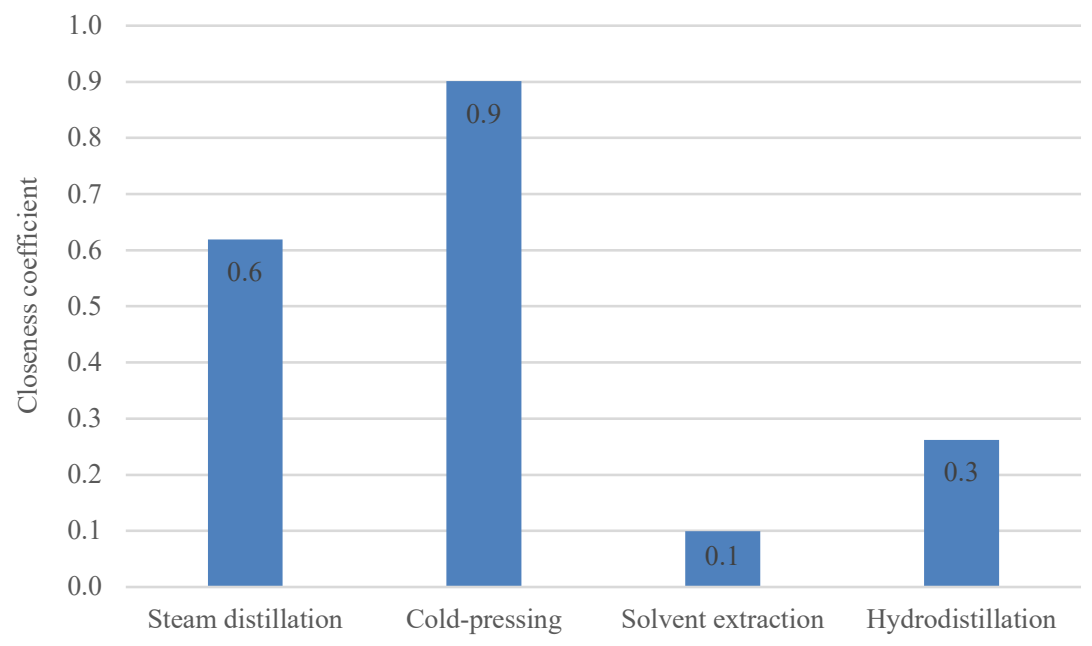

Fig. 3. TOPSIS ranking technologies results.

The TOPSIS analysis results are shown in Fig. 3. Cold pressing (0.9) is the closest alternative for the best solution, not only for the technological criterion that has the highest weight of all criteria (0.45) and good performance in the economical criterion with the second-highest impact on results. Steam distillation ranks as the second technology, with 
evaluation 0.6 , and as a third possible technological solution is hydrodistillation with 0.3 , and solvent extraction -0.1 .

\section{Discussion}

According to the report on the global food waste scenario [26], awareness of food waste has grown. The current research has been made to solve the global problem to some extent. Fruit waste is one of the important areas that need to be focused on. Therefore, this study contributes to minimizing the waste scenario by developing an essential oil extraction pathway from fruit peel waste. The study highlights the use of Multi-Criteria Analysis methods to choose the best extraction technology. By analysing the results, it has been found that in both methodologies AHP and TOPSIS, a cold-pressing method is the best essential oil extraction method.

Several studies have been done on essential oil extraction techniques [22], but our approach provides environmental sustainability by comparing the environmental performances of different alternatives, which leads to the green extraction techniques

However, the MCA methodology requires potential numerical data to perform an analysis. The significant limitation was the lack of quantitative data for the evaluation that cannot negotiate. Therefore, this study suggests that more scientific and laboratory research work is required for more accurate results and to diversify the valorization options.

\section{CONCLuSion}

The main conclusions of this research are drone together and presented in this section. This research aims to determine an approach for the fruit waste valorization pathway and find the best extraction technique. Firstly, a vast literature analysis was performed to identify the essential oil extraction pathway from fruit waste in a more sustainable way. Secondly, Multicriteria analysis was performed to find the best extraction technique considering the technical, environmental, economic \& social aspects.

Within this research, the publicly available data of existing essential oil extraction pathways were studied, and based on that fruit waste valorization pathway was created. Furthermore, to ensure the extraction technique multi-criteria analysis followed by AHP and TOPSIS was successfully performed.

The outcome of the research leads to the conclusion that essential oil is the most crucial and multi-functional product, which can be extracted by the cold-pressing technique. AHP method is used to evaluate the weight of the criterion, which shows that the most effective criteria are the technical criteria. Based on the AHP weight TOPSIS was performed for further evaluation, which shows that the cold-pressing method is the most suitable technique for the extraction. Overall, fruit waste valorization and various alternative techniques considering the various aspects can be evaluated by the Multi-criteria analysis. This research concludes that the new innovative bioresource valorization pathways can be created and evaluated by Multi-criteria analysis.

\section{ACKNOWLEDGEMENT}

This work was supported by the Latvian Council of Science, project "Bioresources Value Model (BVM)", grant No. lzp2018/1-0426. 


\section{REFERENCES}

[1] Esparza I., Jimenez-Moreno N., Bimbela F., Ancín-Azpilicueta C., Gandía M. L. Fruit and vegetable waste management: Conventional and emerging approaches. Journal of Environmental Management 2020:265:110510. https://doi.org/10.1016/j.jenvman.2020.110510

[2] Wadhwa M., Bakshi M. P. S., Makkar H. P. S. Wastes to worth: Value added products from fruit and vegetable wastes. CAB Rev Perspect Agric Vet Sci Nutr Nat Resour. 2016. https://doi.org/10.1079/PAVSNNR201510043

[3] Cristóbal J., Caldeira C., Corrado S., Sala S. Techno-economic and profitability analysis of food waste biorefineries at European level. Bioresource Technology 2018:259:244-252. https://doi.org/10.1016/j.biortech.2018.03.016

[4] Pfaltzgraff L. A., De Bruyn M., Cooper E. C., Budarin V., Clark J. H. Food waste biomass: A resource for high-value chemicals. Green Chem. 2013:15:307-314. https://doi.org/10.1039/c2gc36978h

[5] El Barnossi A., Moussaid F., Iraqi Housseini A. Tangerine, banana and pomegranate peels valorisation for sustainable environment: A review. Biotechnology Reports 2021:29:e00574. https://doi.org/10.1016/j.btre.2020.e00574

[6] Singh B., Singh J. P., Kaur A., Yadav M. P. Insights into the chemical composition and bioactivities of citrus peel essential oils. Food Research International 2021:143:110231. https://doi.org/10.1016/j.foodres.2021.110231

[7] Saleem M., Saeed M. T. Potential application of waste fruit peels (orange, yellow lemon and banana) as wide range natural antimicrobial agent. Journal of King Saud University - Science 2020:32(1):805-810. https://doi.org/10.1016/j.jksus.2019.02.013

[8] Sánchez-Camargo A., Gutierrez L.-F., Vargas S. M., Martinez-Correa H. A., Parada-Alfonso F., Narvaez-Cuenca C.-E. Valorisation of mango peel: Proximate composition, supercritical fluid extraction of carotenoids, and application as an antioxidant additive for an edible oil. The Journal of Supercritical Fluids 2019:152:104574. https://doi.org/10.1016/j.supflu.2019.104574

[9] Özogul Y., Özogul F., Kulawik P. The antimicrobial effect of grapefruit peel essential oil and its nanoemulsion on fish spoilage bacteria and food-borne pathogens. LWT 2021:136(P2):110362. https://doi.org/10.1016/j.lwt.2020.110362

[10] Güzel M., Akpınar Ö. Valorisation of fruit by-products: Production characterization of pectins from fruit peels. Food and Bioproducts Processing 2019:115:126-133. https://doi.org/10.1016/j.fbp.2019.03.009

[11] Chen F., Jia J., Zhang Q., Gu H., Yang L. A modified approach for isolation of essential oil from fruit of Amorpha fruticosa Linn using microwave-assisted hydrodistillation concatenated liquid-liquid extraction. Journal of Chromatography A 2017:1524:254-265. https://doi.org/10.1016/j.chroma.2017.10.008

[12] Besombes C., Berka-Zougali B., Allaf K. Instant controlled pressure drop extraction of lavandin essential oils: Fundamentals and experimental studies. Journal of Chromatography A 2010:1217(44):6807-6815. https://doi.org/10.1016/j.chroma.2010.08.050

[13] Shao Q., Deng Y., Liu H., Zhang A., Huang Y., Xu G., Li M.. Essential oils extraction from Anoectochilus roxburghii using supercritical carbon dioxide and their antioxidant activity. Industrial Crops and Products 2014:60:104-112. https://doi.org/10.1016/j.indcrop.2014.06.009

[14] Saaty T. L. A scaling method for priorities in hierarchical structures. Journal of Mathematical Psychology 1977:15(3):234-281. https://doi.org/10.1016/0022-2496(77)90033-5

[15] Hwang C.-L., Yoon K. Multiple Attribute Decision Making: Methods for Multiple Attribute Decision Making. Berlin: Springer Berlin Heidelberg, 1981:58-191. https://doi.org/10.1007/978-3-642-48318-9

[16] Račko E., Blumberga D., Spalviņš K., Marčilautiene E. Ranking of by-products for single cell oil production. Case of Latvia. Environmental and Climate Technologies 2020:24(2):258-271. https://doi.org/10.2478/rtuect-2020-0071

[17] Kudurs E., Tukulis A., Dzalbs A., Blumberga D. Are Industries Open for Renewable Energy? Environmental and Climate Technologies 2020:24(3):447-456. https://doi.org/10.2478/rtuect-2020-0115

[18] Yadav A. A., Chikate S. S., Vilat R. B., Suryawanshi M. A., Kumbhar G. B. Review on steam distillation: a promising technology for extraction of essential oil. International Journal of Advance Engineering and Research Development 2017:4(4):667-671. https://doi.org/10.21090/ijaerd.33095

[19] Çakaloğlu B., Özyurt V. H., Ötleş S. Cold press in oil extraction. A review. Ukrainien Food J. 2018:7(4):640-654. https://doi.org/10.24263/2304-974x-2018-7-4-9

[20] Dangkulwanich M., Charaslertrangsi T. Hydrodistillation and antimicrobial properties of lemongrass oil (Cymbopogon citratus, Stapf): An undergraduate laboratory exercise bridging chemistry and microbiology. Food Science Education 2020:19(2):41-48. https://doi.org/10.1111/1541-4329.12178

[21] Costa G. A., Santos R. G. dos. Fractionation of tire pyrolysis oil into a light fuel fraction by steam distillation. Fuel 2019:241:558-563. https://doi.org/10.1016/j.fuel.2018.12.075

[22] Masango P. Cleaner production of essential oils by steam distillation. Journal of Cleaner Production 2005:13(8):833839. https://doi.org/10.1016/j.jclepro.2004.02.039

[23] Chew S. C. Cold-pressed rapeseed (Brassica napus) oil: Chemistry and functionality. Food Research International 2020:131:108997. https://doi.org/10.1016/j.foodres.2020.108997

[24] Yang W., Wang X., Ni S., Liu X., Liu R., Hu C., Dai H. Effective extraction of aromatic monomers from lignin oil using a binary petroleum ether/dichloromethane solvent. Separation and Purification Technology 2021:267:118599. https://doi.org/10.1016/j.seppur.2021.118599 
[25] Oreopoulou A., Tsimogiannis D., Oreopoulou V. Chapter 15 - Extraction of Polyphenols From Aromatic and Medicinal Plants: An Overview of the Methods and the Effect of Extraction Parameters. Polyphenols in Plants, $2^{\text {nd }}$ ed. Amsterdam: Elsevier, 2019:243-259. https://doi.org/10.1016/b978-0-12-813768-0.00025-6

[26] Dou Z., Toth J. D. Global primary data on consumer food waste: Rate and characteristics - A review. Resources, Conservation and Recycling 2021:168:105332. https://doi.org/10.1016/j.resconrec.2020.105332 